\title{
Effect of Rice Bran on Continuous Organic Waste Decomposition Processes
}

\author{
Reni Sutri Suherman ${ }^{1}$, Yuri Yamaguchi ${ }^{1}$, Akira Yanagihara ${ }^{1}$, Tadashi Yamauchi ${ }^{1} \&$ Satoshi Matsuda $^{1}$ \\ ${ }^{1}$ Graduate School of Science and Technology, Shizuoka University, Japan \\ Correspondence: Satoshi Matsuda, Graduate School of Science and Technology, Shizuoka University, Japan. Tel: \\ 053-478-1173, ext+81. E-mail: matsuda.satoshi@shizuoka.ac.jp
}

\author{
Received: April 25, 2019 Accepted: May 6, 2019 Online Published: May 30, 2019 \\ doi:10.5539/eer.v9n1p61 URL: https://doi.org/10.5539/eer.v9n1p61
}

\begin{abstract}
The mirobial decomposition process of househole waste, mainly food waste, is considered an environmentally friendly way to treat organic wastes. However, there are some problems which often occur, such as low conversion rate and bad smell generation, especially in the early stage of continuous operation systems. Rice bran has been known empirically as an acclerator or improving material for the microbial decomposition process of organic wastes. Unfortuantely, little information about the detailed findings has been obtained so far.

This study intended to analyze the effect of rice bran as an activating agent in organic waste decomposition in order to minimalize the problems. Firstly, the effect of rice bran was confirmed. Reactor weight, temperature, moisture content, $\mathrm{pH}$, and microbe number were measured and used as the parameters to confirm the effect of rice bran addition in the decomposition process. It was observed that the total waste reduction during the process was larger in the case of rice bran addition than that of the blank, i.e. without rice bran addition. The other parameters also showed similar tendencies, indicating that rice bran is surely capable of activating the decomposition process. Then, the growth accelerating effect for microorganisms in the composting process was examined by a cultivation test using trypticase-soy liquid medium. The microbe number in the medium with rice bran addition was higher than the medium without rice bran.

Secondly, the factors contributing this effect were searched. Although we could narrow down the number of candidate constituent, among them magnesium was one of the major candidates, the precise identification was not possible, possibly because the effect of each nutrient on the microbes varies depending on the kind of microbial strain, and not a single but a combination of multiple nutrients may cause this effect. However, it was confirmed as a whole that rice bran shows a good influence on the growth of many micorbes in the composting process and accelerates the performance of decomposition.
\end{abstract}

Keywords: rice bran, continuous composting, microbial decomposition process, organic waste

\section{Introduction}

Household waste disposal has been a study topic for several decades (Haug, 1993: Pearce and Brisson, 1995: U.S. EPA, 1995: Morgan, 2006). The problems are its large amount in total domestic waste and its difficulty to be treated (Matsuda, 2016). Most domestic waste in Japan is treated with an incineration process, which has a financial burden (Maruchi and Matsuda, 2016). While in Indonesia and other many developing countries, mostly landfill treatment is used, which generates environmental and health problems (Kinantan et al, 2018; Uriarte Jr., 2008; Ramachandra, 2006; Zorpas et al, 2017; Aziz and Amr, 2016; Tammemagi, 1999).

The United Nations, Food and Agriculture Organization (FAO) stated that global quantitative food losses and waste per year are about $30 \%$. Moreover, food waste has been considered as the major content in household waste (Walsh and Jones, 1991). Reflecting on its large amount in household waste and the organic content, the microbial garbage treatment system is considered as an alternative way for household waste disposal (Matsuda et al, 2017). Nevertheless, in the development of this system, another problem occurred, such as low decomposition rate in the early stage of the process and decreasing of decomposition rate when overloading phenomena occurred (Maruchi and Matsuda, 2016).

In the previous study in our laboratory, rice bran was reported as having a good effect on reducing the weight of the microbial garbage treatment process (Takenaka, 2013). It was assumed that the changing of bulk density 
increased the efficiency of the process. However, Chang and Chen (2010) stated that rice bran was not a bulking agent in the food composting process. Rice bran is a by-product from the milling process of paddy rice to produce polished rice, which contains $12-20 \%$ of total kernel weight (Epstein, 2017). Rice bran has been reported to have a good effect to optimize the composting process since it contains some essential material for microorganism metabolism (Moongngarm et al, 2012; Budihardjo et al, 2018). Rice bran consists of many materials which are essential to microbial growth in organic solid waste composting processes. However, the influence of these materials to microorganism metabolism is not yet known.Therefore, another approach to understand this effect is needed. This study intends to examine the rice bran effect in microbial activity during the microbial garbage treatment process.

\section{Method}

\subsection{Discovered Facts from Previous Study}

The previous study about the candidate of effective material in rice bran, which activates microbe growth, was conducted in our laboratory by Akira Takenaka (2013). From the research results, some facts were discovered.

1. Refine microbial activation substances by fractionation analysis

Molecular weight fraction dialysis of rice bran material was done to observe the molecular range, which affects the rice bran effect on microbial growth. As the results:

a. Microbial activation materials are water-soluble, because water extraction of rice bran shows the same effect as that with no treatment.

b. Microbial activation materials have molecular weight below 1,000 and resistance against heat (boiling), suggesting that proteins can be excluded from the candidates.

2. Search for microbial activators

At the first stage, the ingredients of the activating materials were compared to the nutrient medium. Based on the comparison, the possible substances were narrowed down. Therefore, the verification of the substances that may activate microorganisms such as sugars, amino acids, vitamins, and mineral was conducted. As the results:

a. The amount of each amino acid and sugar derived from activating material is about 1 to $20 \%$. It is unlikely that amino acids and sugar are candidate substances.

b. From the vitamins group: nicotinic acid, pyridoxine, and thiamine seem to be possible as candidates which activate material.

c. Magnesium seems to be possible as a candidate which activates material from the inorganic material group.

As the continuation on Akira Takenaka's research, four candidate materials: nicotinic acid, pyridoxine, thiamine, and magnesium were chosen for further study.

\subsection{Observation of Rice Bran Addition Effect in OrganicWaste Decomposition Processes}

\subsubsection{Materials and Method}

Dog food as a model organic waste was used as the input with rate $40 \mathrm{~g} /$ (L.day) and a moisture content of $70 \%$. Waste was input to a static-type garbage treatment system, which was developed in our laboratory. As a bulking agent, $10 \mathrm{~L}$ leaf mold was used. Rice bran was added in the first day only, with a ratio of 1:8 to the leaf mold weight (wet basis). The rice bran moisture content was adjusted to leaf mold moisture content before addition. Manual mixing was performed once a day when waste was input to maintain the aerobic condition and the system mixture.

\subsubsection{Measurement of Physical Parameters}

Physical parameters measurement was done twice a day before inputting waste and six hours after inputting. Temperature, reactor weight, and moisture content were measured everyday for seven days. Sample pH was measured every two days.

\subsubsection{Analysis of Microbe Number}

This analysis was done for every two days with a trypticase-soy medium as the medium. The microbe was inoculated from a $3 \mathrm{~g}$ sample and $27 \mathrm{~g}$ distilled water. The mixture was homogenized for 10 minutes with 10,000 $\mathrm{rpm}$. Then, the solution was diluted with factor $10^{7}$ and $10^{8}$ before inoculation. The microbe number was counted after seven days of inoculation. 


\subsubsection{Analysis of Microbial Growth}

One mixture consists of $88 \mathrm{ml}$ trypticase-soy medium, $2 \mathrm{ml}$ extracted microbe from leaf mold and $10 \mathrm{ml}$ extract rice bran was prepared. Another mixture used $10 \mathrm{ml}$ sterilized water instead of rice bran, as the negative control. The mixture was cultured under a temperature of $40^{\circ} \mathrm{C}$ for 12 hours. Samples were taken at 6,9 and 12 hours, then optical density value was measured using spectrophotometer with a $610 \mathrm{~nm}$ wavelength. The outline of the experiment was shown in Fig. 1.

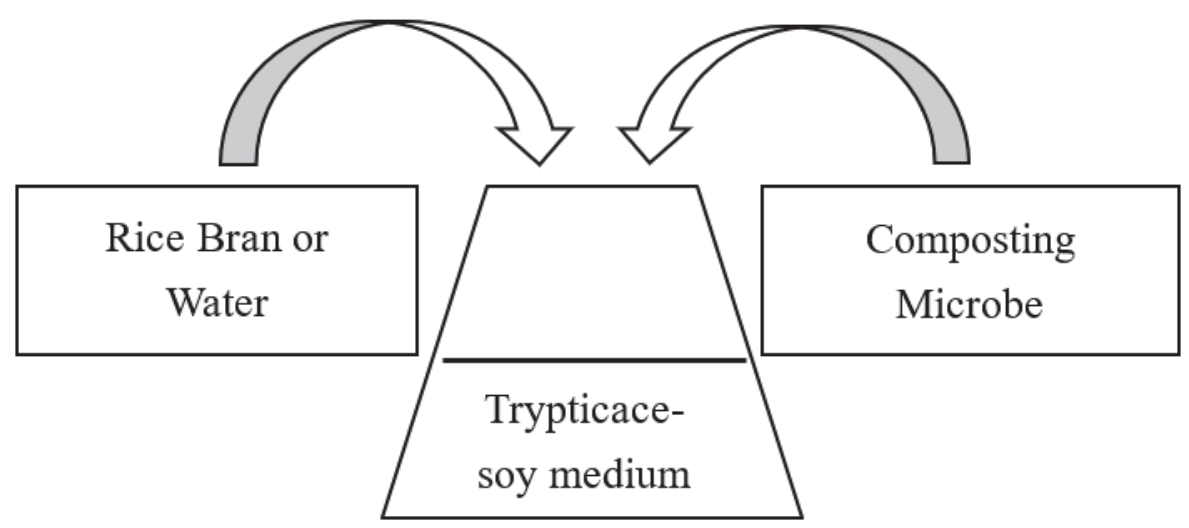

Figure 1. Analysis of Microbial Growth Mixture

Extracted microbes were obtained from pure leaf mold sample without any organic waste input. Three grams of leaf mold was sampled and $27 \mathrm{~g}$ distilled water was added. The mixture was homogenized for 10 minutes at 10,000 $\mathrm{rpm}$. Then, the solution was diluted with a dilution factor of $10^{4}$.

Extract rice bran was prepared by dissolving $10 \mathrm{~g}$ rice bran powder in $100 \mathrm{~mL}$ sterilized water and the mixture was stirred for 10 minutes. Then, the extracted material was separated using a centrifuge for 30 minutes at a speed of $8000 \mathrm{rpm}$. The supernatant fluid was taken as rice bran extract.

\subsection{Observation of Microbial Growth in Liquid Medium with Additional Materials}

The experimental method mainly referred to Takenaka's method. All of the $100 \mathrm{~mL}$ mixtures, contained $88 \mathrm{~mL}$ of trypticase-soy medium, $2 \mathrm{~mL}$ extracted microbes (from soil with $10^{4}$ dilution) and $10 \mathrm{ml}$ of various activating agents (Positive Control (PC) was rice bran, Negative Control (NC) was sterilized water) were prepared. The mixtures were cultured for 9 hours at $37^{\circ} \mathrm{C}$.

We checked the effect on the microbial growth of combinations of the four candidate materials found in the previous study. The sample combinations are shown in Table 1.

Table 1. Sample Combinations

\begin{tabular}{lllll}
\hline Solution Activating Material & Pyridoxine & Nicotinic Acid & Magnesium Sulfate & Thiamine \\
\hline No Pyridoxine & & $\circ$ & $\circ$ & $\circ$ \\
No Nicotinic Acid & $\circ$ & & 0 & 0 \\
No Magnesium & $\circ$ & $\circ$ & & 0 \\
No Thiamine & $\circ$ & $\circ$ & $\circ$ & \\
All & $\circ$ & 0 & 0 & \\
Only Pyridoxine & $\circ$ & & & \\
Only Nicotinic Acid & & $\circ$ & 0 & 0 \\
Only Magnesium & & & & \\
Only Thiamine & & &
\end{tabular}

The content of pyridoxine, nicotinic acid, magnesium and thiamin in $10 \mathrm{~mL}$ extracted rice bran are $0.280 \mathrm{mg} / 100$ $\mathrm{mL}, 4.990 \mathrm{mg} / 100 \mathrm{~mL}, 0.240 \mathrm{mg} / 100 \mathrm{~mL}$ and $151 \mathrm{mg} / 100 \mathrm{~mL}$, respectively. However the materials used were not pure, therefore recalculation was needed. As the used amount of pyridoxine and thiamine was really small, 
solutions with hundred times concentration were preparedand dilutions were performed.

\subsection{Observation of Additional Materials Variety in Microbial Growth}

The experimental method referred to Takenaka's method in point 2.3. The variety of additional materials was chosen from Wako Chemical Catalog, $39^{\text {th }}$ edition. Pyridoxine does not have other form. Therefore, the identification of pyridoxine effectiveness could not be done. Activating agents used in this experiment are shown in Table 2.

Table 2. Activating agents for this experiment

\begin{tabular}{lll}
\hline Materials & Formula & Used amount (mg) \\
\hline Thiamine hydrochloride & $\mathrm{C}_{12} \mathrm{H}_{17} \mathrm{ClN}_{4} \mathrm{OS}-\mathrm{HCl}$ & 0.305 \\
Thiamine nitrate & $\mathrm{C}_{12} \mathrm{H}_{17} \mathrm{~N}_{4} \mathrm{OS}-\mathrm{NO}_{3}$ & 0.290 \\
Magnesium sulfate & $\mathrm{MgSO}_{4} \cdot 7 \mathrm{H}_{2} \mathrm{O}$ & 1531 \\
Magnesium nitrate & $\mathrm{Mg}\left(\mathrm{NO}_{3}\right)_{2} \cdot 6 \mathrm{H}_{2} \mathrm{O}$ & 1593 \\
Magnesium chloride & $\mathrm{MgCl}_{2} \cdot 6 \mathrm{H}_{2} \mathrm{O}$ & 844.8 \\
\hline
\end{tabular}

\subsection{Observation of Additional Materials to Isolated Microbes}

Experimental method referred to Takenaka's method in point 2.3. Microbes used in this experiment were obtained from isolated microbe from composting process. Seven kinds of isolated microbe were used which are distinguished by color and shape, as displayed in Table 3.

Table 3. Variety of Isolated Microbe Used

\begin{tabular}{|c|c|c|c|c|c|}
\hline $\begin{array}{c}\text { Microbe } \\
\text { Name }\end{array}$ & Color and Shape & Picture & $\begin{array}{c}\text { Microbe } \\
\text { Name }\end{array}$ & Color and Shape & Picture \\
\hline W1 & $\begin{array}{l}\text { White, circular } \\
\text { hemispherical }\end{array}$ & & B1 & $\begin{array}{l}\text { Beige, circular } \\
\text { hemispherical }\end{array}$ & \\
\hline W1' & White, circular flat & & Y1 & $\begin{array}{l}\text { Yellow, circular } \\
\text { hemispherical }\end{array}$ & \\
\hline W2 & White, irregular flat & & $\mathrm{O} 1$ & $\begin{array}{l}\text { Orange, circular } \\
\text { hemispherical }\end{array}$ & \\
\hline $\mathrm{P} 1$ & $\begin{array}{l}\text { Pink, circular } \\
\text { hemispherical }\end{array}$ & & & & \\
\hline
\end{tabular}

\section{Result and Discussion}

\subsection{Observation of Rice Bran Addition Effect in OrganicWaste Decomposition Process}

\subsubsection{Comparison of Normal Composting and Rice Bran Addition Composting}

The comparison of the reactor weight between normal composting and rice bran addition composting to the total input weight is shown in Fig. 2. From this graph, the reactor weight of rice bran addition composting decreased more than normal composting. The beneficial effect of rice bran addition to the composting process can be observed from the difference in weight reduction. The same results could be obtained repeatedly, meaning that repeatability of the experiment was confirmed. 


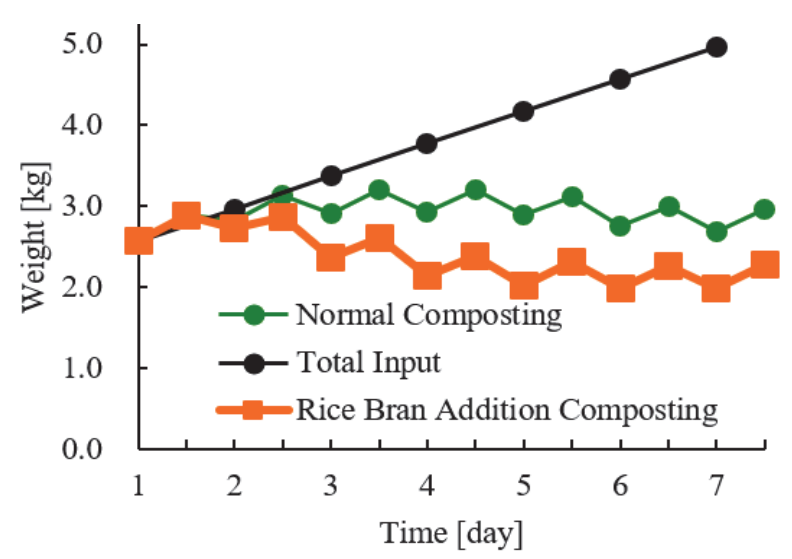

Figure 2. Comparison of Reactor Weight between Normal Composting and Rice Bran Addition Composting to Total Input Weight

\subsubsection{Physical Parameter Change}

\section{Temperature Change}

The temperature change during the composting process between normal composting and rice bran addition composting can be seen in Fig. 3. Normal waste decomposition process is an aerobic oxidation of organic compounds, which generates heat from the exothermic reaction process (Matsuda, 2016). Therefore, reactor temperature is a good parameter to know about the decomposition process in the reactor. In rice bran addition composting, temperature rose within the first day and reached the highest temperature within six hours after waste input on the second day. Before waste was input the temperature was lower than six hours after input. It was observed that the decomposition process happened after the waste was input. On the other hand, the temperature of normal composting rose in the second day and was not as high as rice bran addition composting.

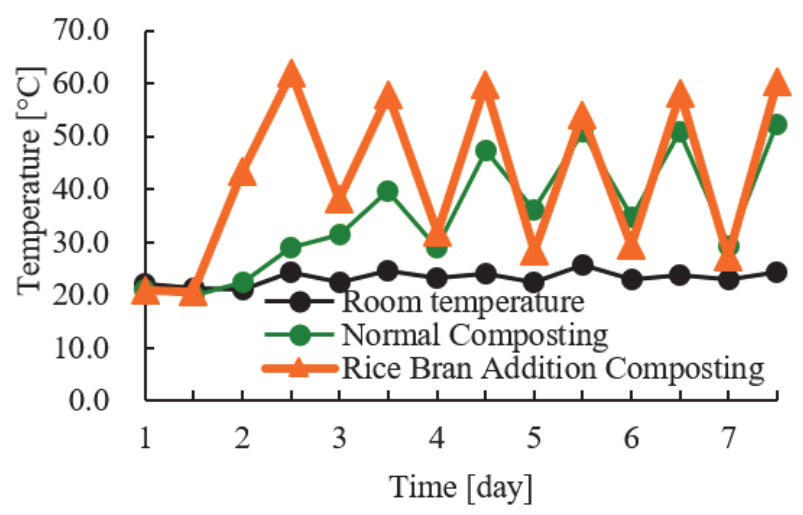

Figure 3. Temperature Change During Normal Composting and Rice Bran Addition Composting Process

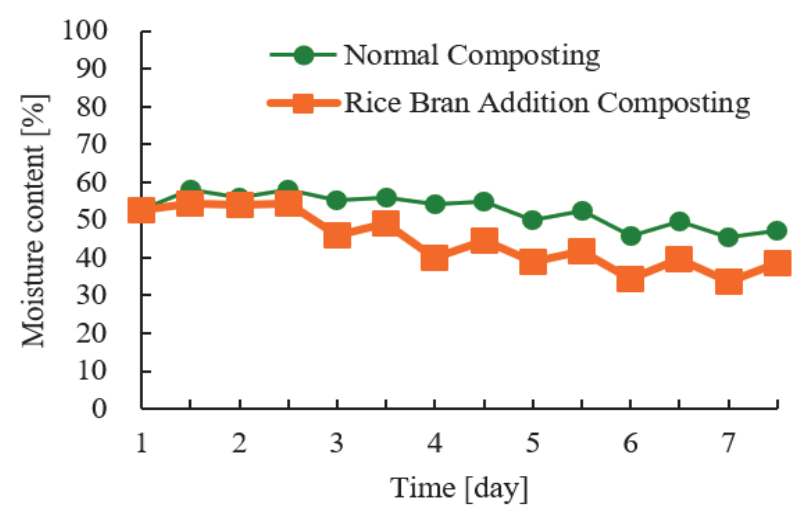

Figure 4. Moisture Content Change During Normal Composting and Rice Bran Addition Composting Process 


\section{Moisture Content Change}

The change of moisture content during the process is shown in Fig. 4. During the composting process, the moisture content of rice bran addition composting decreased more than normal composting. The higher temperature and greater bulk density in rice bran addition composting is affected by the larger water loss during the composting process.

\section{3. pH Change}

The $\mathrm{pH}$ change during the composting process is displayed in Fig. 5. Both $\mathrm{pH}$ of normal composting and rice bran addition composting did not show a significant drop. During the decomposition process, various organic acids are produced if the anaerobic condition occurred, resulting in a pH drop (Haug, 1993). The aerobic condition was maintained during both composting process, and the addition of rice bran did not affect the $\mathrm{pH}$ in the reactor.

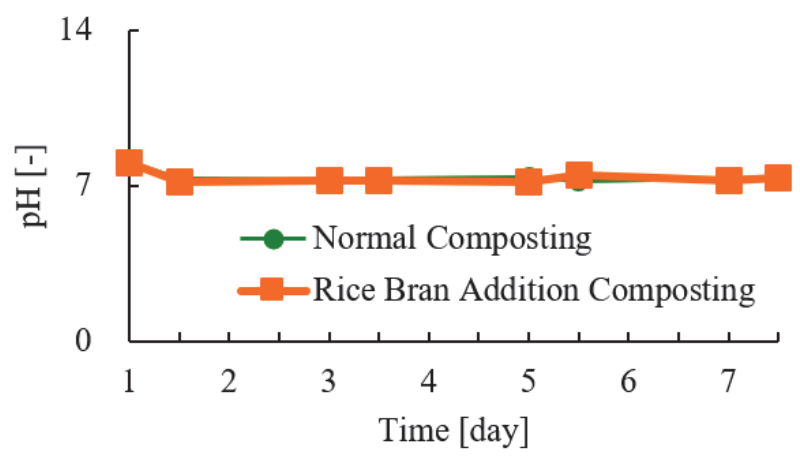

Figure 5. pH Change During Normal Composting and Rice Bran Addition Composting Process

\subsubsection{Analysis of Microbe Number}

Microbe number of normal composting and rice bran addition composting is shown in Fig. 6. Six hours after the first input, the microbe number in rice bran addition composting increased rapidly, while the temperature of the process was not increased. There is a possibility that in the early stage of rice bran addition composting, some materials in rice bran affected the microbe reproduction enzyme. Therefore, if the reproduction process happened in rice bran addition composting, the greater number of microbes will be easily decompose the same amount of waste compared to normal composting. It was observed that the rice bran addition temperature on the second day before input was high, which indicated that decomposition process happened.

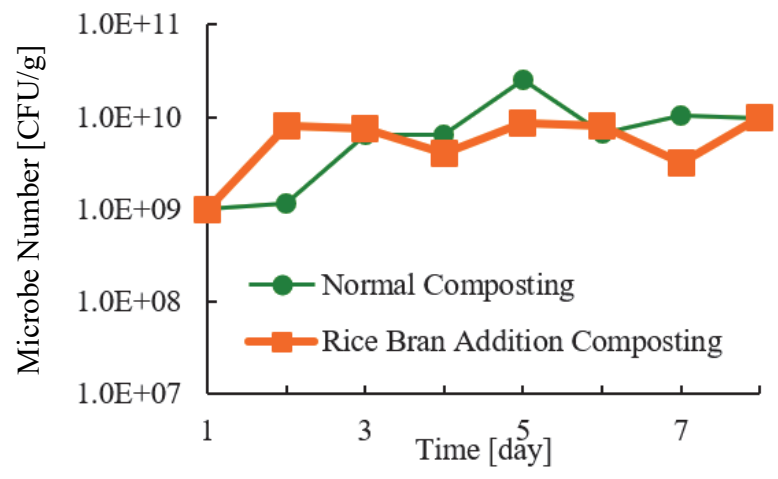

Figure 6. Microbe Number Change During Normal Composting and Rice Bran Addition Composting Process

\subsubsection{Analysis of Microbial Growth}

The growth of composting microbes in a liquid medium is shown in Fig. 7. Microbial growth in the trypticase-soy medium with rice bran as a supplement, showed higher optical density value compared with a negative control. This means that the microbe number in the medium with rice bran was more than in the medium without rice bran. A significant increase was observed between 6 and 9 hours after inoculation. It was confirmed that rice bran has a good effect in increasing microbe number. Therefore, the activation of the early stage of composting with rice bran was possible because a plentiful amount of microbes were present in the decomposition process. 


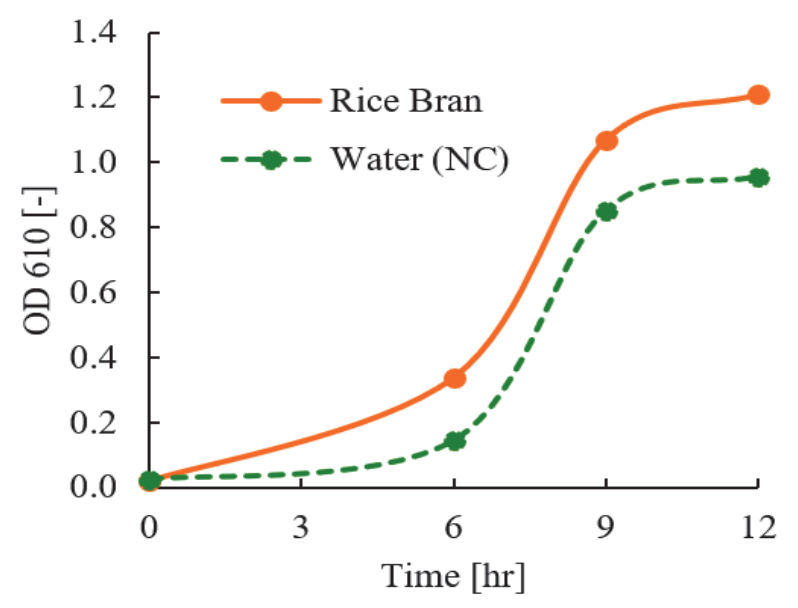

Figure 7. Growth of Composting Microbe in 12 hours measured with Optical Density Method

\subsection{Observation of Microbial Growth in Liquid Medium with Additional Materials}

Sampling from eleven solutions was conducted every $0,6,7.5$ and 9 hours. Then $\mathrm{OD}_{610}$ were measured for each sample using spectrophotometer with a $610 \mathrm{~nm}$ wavelength.

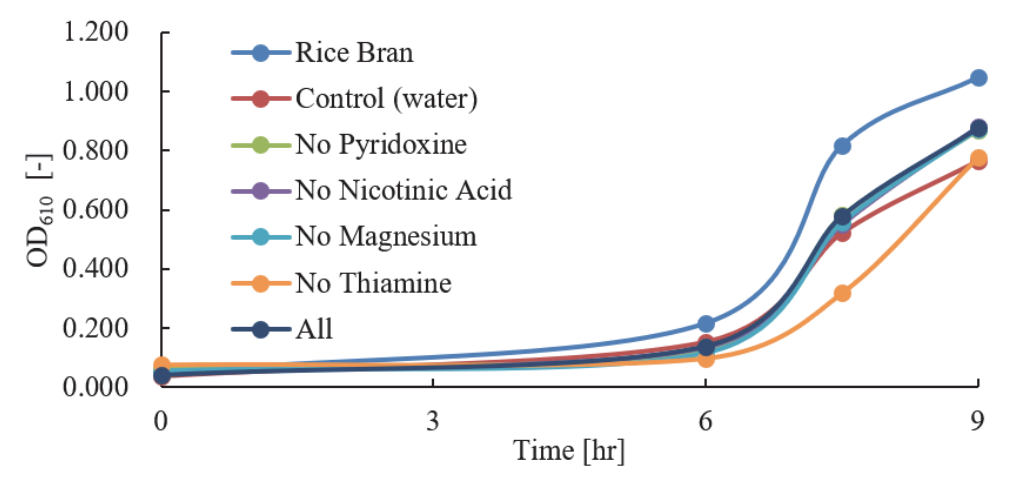

Figure 8. $\mathrm{OD}_{610}$ Value of Combination Solution compared with Positive (rice bran) and Negative (water) Control

Based on Fig. 8, all combination samples showed better result than the negative control, except for the solution without thiamine. It is assumed that the presence of thiamine is essential for composting microbe growth, since the absence of thiamine showed similar results as the negative control.

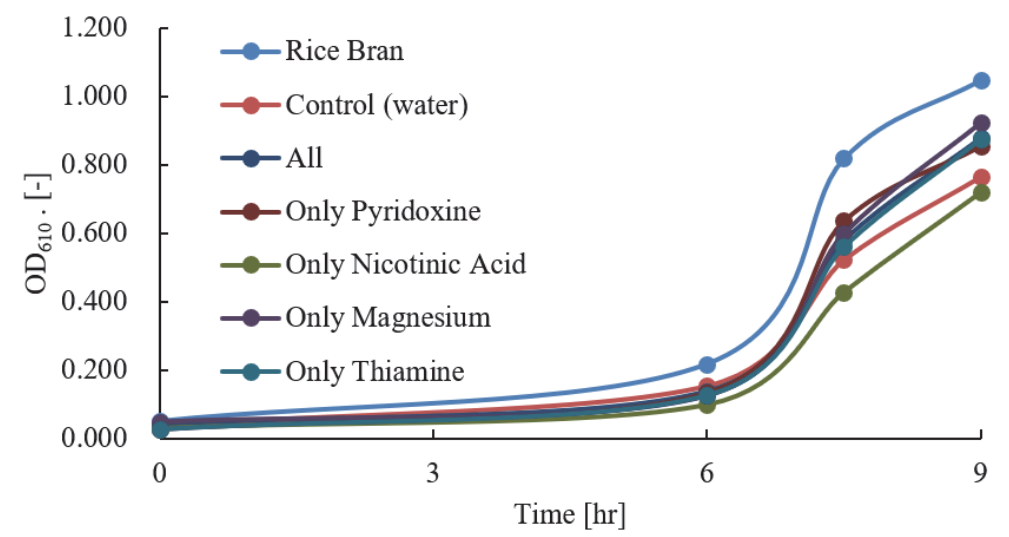

Figure 9. $\mathrm{OD}_{610}$ Value of without Combination Material compared with Positive (rice bran) and Negative (water) Control

From Fig. 9, the solution with magnesium showed the best optical density value among other solutions, magnesium is probably an essential activating agent, while the solution with nicotinic acid showed worse optical density value 
than negative control. It is assumed that nicotinic acid is not really essential for composting microbe growth.

\subsection{Observation of Additional Materials Variety in Microbial Growth}

In the previous experiment, the presence of pyridoxine, thiamine and magnesium in the solution showed a higher optical density value than the negative control. However, the materials used in the experiment were not pure. Therefore, confirmation of whether, pyridoxine, thiamine and magnesium are the effective materials or the other bound compound is needed.

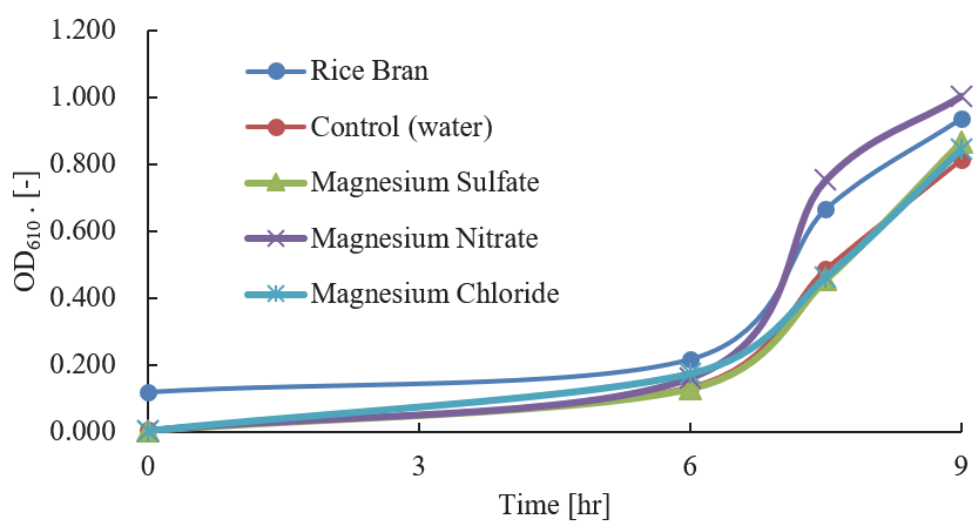

Figure 10. $\mathrm{OD}_{610}$ Value of Various Magnesium Solutions compared with Positive (rice bran) and Negative (water) control

Figure 10 shows all kinds of magnesium have better optical density than the negative control. The effect of magnesium to activate composting microbe growth was confirmed. In addition, the solution consists of magnesium nitrate as the activating agent had a higher optical density value compared to the positive control. There is a possibility that when the ions of magnesium and nitrate had formed in the solution, composting microbes got extra nutrient from the nitrate, since nitrate is natural form of nitrogen in soil. Therefore, magnesium nitrate showed better results than the positive control.

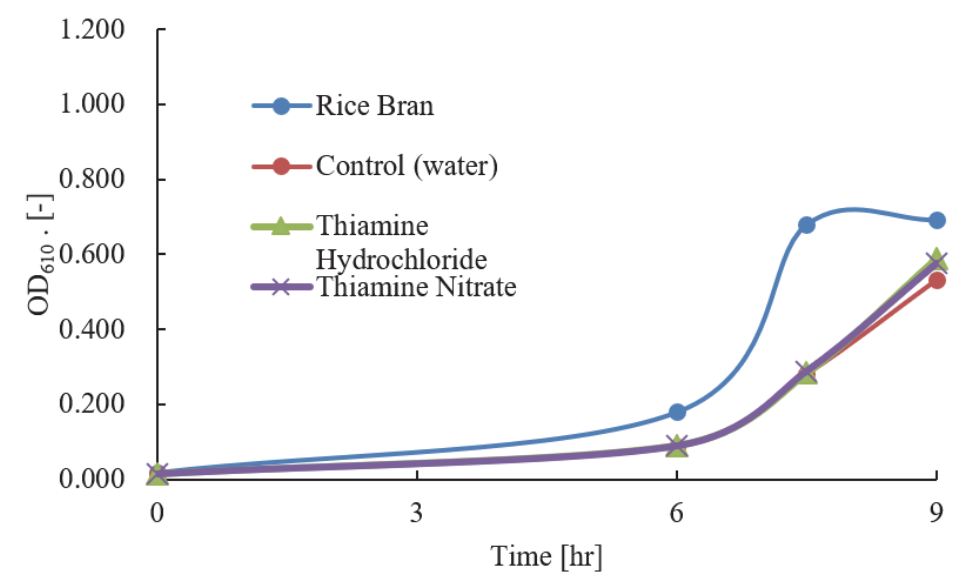

Figure 11. $\mathrm{OD}_{610}$ Value of Various Thiamine Solutions compared with Positive (rice bran) and Negative (water) control

From Fig. 11, both thiamine solutions had higher optical density value than the negative control. The effect of thiamine to activate composting microbe growth is confirmed. Both kinds of thiamine (thiamine hydrochloride and thiamine nitrate) have similar effects in composting microbe growth.

\subsection{Observation of Additional Materials in Isolated Microbes}

The activity of every microbe in each activating agent is shown in Fig. 12. Those figures are a summary of all seven microbe activities in each activating agent by subtracting the optical density value with the negative control optical density value. A minus value means the microbe activity in the activating agent solution showed worse 
results than water as a negative control. A plus value means the microbe activity in the activating agent solution showed better results than the negative control. The effects of the materials on every microbe were all different from each other, indicating that the situation is more complicated than we thought. This result may suggest that the effect of each nutrient on the microbes varies depending on the kind of microbial strain, and not a single but a combination of multiple nutrients can cause this effect.

All kinds of microbes, with the exception of B1 and P1, showed a plus value in thiamine solution. Therefore, the presence of thiamine is needed for these microbes. While pyridoxine solutions P1, W1', O1 and W2 indicated incredibly high optical density value, it seemed likely that the existence of pyridoxine in the solution affected the microbe's growth. In magnesium sulfate solution, B1 had an exceptionally high optical value compared to other microbes. During the composting process, B1 is considered to be a huge microbe colony, which always appeared. Therefore, in all composting microbe activity, magnesium showed the best results due to the abundant amount of B1 microbe that has a preference toward magnesium.

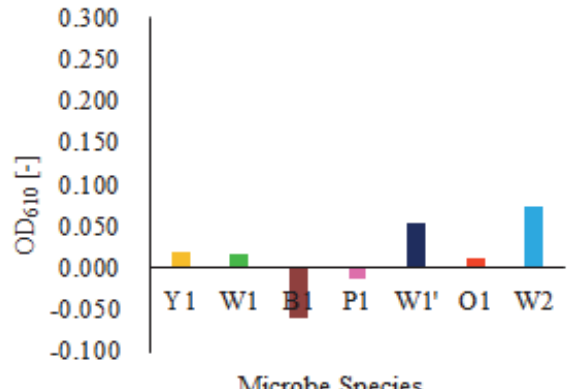

(a) Thiamine

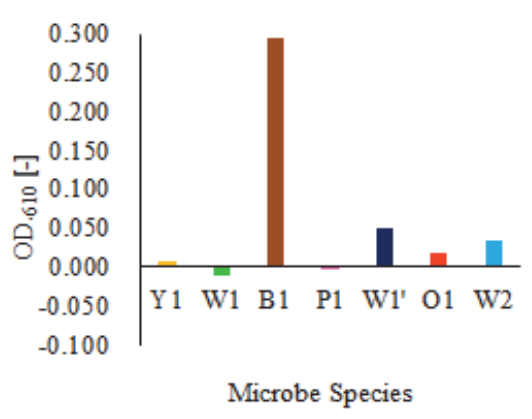

(c) Magnesium Sulfate

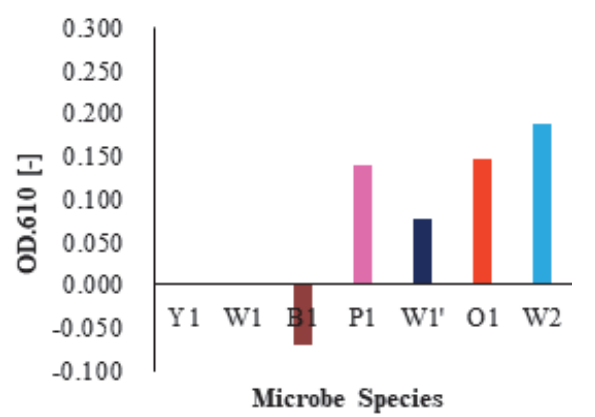

(b) Pyridoxine

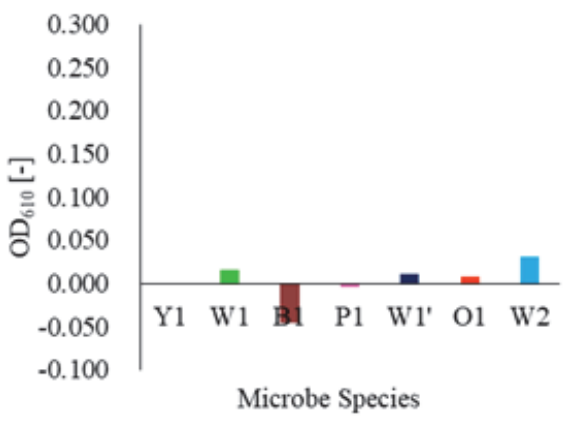

(d) Nicotinic Acid

Figure 12. Microbes Activity in Activating Agent Solutions

On the other hand, in overall composting microbe activity, microbes grew in nicotinic acid solution and showed worse results than the negative control. As well as in the activity of each microbe, most of the microbes probably do not really need nicotinic acid as activating agents.

\section{Conclusion}

It was observed that rice bran addition in the composting process could activate the early stage of the decomposition process. Within one day, the decomposition process started. The activation process was concluded as the effect of rice bran addition to the microbial community in the composting process.

Several materials in rice bran are considered to have an influence in the composting microbe reproduction process. The effects of the materials on every microbe were all different from each other, indicating that the situation is rather complicated. This result may suggest that the effect of each nutrient on the microbes varies depending on the kind of microbial strain, and not a single but a combination of multiple nutrients can cause this effect.

However, further study is needed to prove this assumption. Since in the early stage, the activation of the decomposition process in rice bran addition composting occurred, the weight of waste created in the process was reduced to a greater extent than normal composting. 
In addition, from the experiments, it was found that magnesium is a substantial material in rice bran, which affects composting microbe growth. Composting microbes consist of various kinds of microorganisms, which have their own preferential material. During the composting process, B1 microbe frequently appears inplentiful number. Moreover, B1 showed extremely high activity in the presence of magnesium. Therefore, magnesium seems to have a substantial effect in composting microbe growth.

\section{References}

Aziz, H. A., \& Amr, S. A. (2016). Control and Treatment of Landfill Leachate for Sanitary Waste Disposal. United States of America: IGI Global, Hershey (pp. xiv)

Budihardjo, M. A., Sutrisno, E., Purwono, \& Fatimah, M. (2018). Leaves Composting Process and the Influence of Rumen Content and Bran Addition. MATEC Web of Conference, 01033

Chang, J. I., \& Chen, Y. J. (2010). Effect of Bulking Agents on Food Waste Composting. Elsevier; Journal Bioresource Technology, 101, 5917-5924. https://doi.org/10.1016/j.biortech.2010.02.042

Epstein, E. (2017). The Science of Composting. New York: CRC Press (pp. 16)

Food and Agriculture Organization. (n/a). http://www.fao.org/savefood/resources/keyfindings/en/

Haug, R. T. (1993). The practical Handbook od Compost Engineering. Florida: Lewish Publishers (pp. 717)

Kinantan, B., Matondang, A. R., \& Hidayati, J. (2018). Waste Management as an Effort to Improve Urban Area Cleanliness and Community Income (Journal Review). IOP Conf. Series: Material Science and Engineering, 309, 012017. https://doi.org/10.1088/1757-899X/309/1/012017

Maruchi, T., \& Matsuda, S. (2016). Analysis of Overload Phenomenon in Garbage Decomposition. The Japan Society of Applied Physics, JJAP Conf. Proc., 4, 011405.

Matsuda, S. (2016). Engineering of Microbial Garbage Treatment Plants. The Japan Society of Applied Physics, JJAP Conf. Proc., 4, 011401.

Matsuda, S., Maruchi, T., Shimizu, T., \& Itaya, S. (2017). Development of Static Type Garbage Treatment System. Cogent Environmental Science, 3, 1322766.

Moongngarm, A., Daomukda, N., \& Khumpika, S. (2012). Chemical Compositions, Phytochemicals and Antioxidant Capacity of Rice Bran, Rice Bran Layer and Rice Germ. Elsevier, APCBEEProcedia, 2, 73-79.

Morgan, S. (2006). Waste, Recycling and Reuse. East Sussex: White-Thompson Publishing Ltd. (pp. 5-6).

Pearce, D. W., \& Brisson, I. (1995). Waste Treatment and Disposal. Bath: The Royal Society of Chemistry (pp. 131).

Ramachandra, T. V. (2006). Management of Municipal Solid Waste. New Delhi: TERI Press (pp. 2-4).

Takenaka, A. (2013). A Search for Microbial Acrivators in Garbage Decomposition Process. Hamamatsu: Shizuoka University Master Thesis (in Japanese).

Tammemagi, H. (1999). The Waste Crisis, Landfills, Incinerators and the Search for a Sustainable Future. Oxford: Oxford University Press (pp. 4-6).

U.S. Environmental Protection Agency. (1995). Composting Yard and Municipal Solid Waste. Pennsylvania: TechnomicPublishing Co. Inc. (pp. 16).

Uriarte, Jr., F. A. (2008). Solid Waste Management Principles and Practices, An Introduction to the Basic Functional Elements of Solid Waste Management, with Special Emphasis on the Needs of Developing Countries. Quezon City: The University of Philippines Press (pp. 2).

Walsh, J. F., \& Jones, K. H. (1991). Health Effects of Municipal Waste Incineration. Florida: CRS Press (pp. 374).

Zorpas, A. A., Lasaridi, K., Pociovalisteanu, D. M., \& Loizia, P. (2017). Monitoring and Evaluation of prevention Activities regarding Household Organic Waste from Insular Communities. Elsevier. Journal of Cleaner Production, 172, 3567-3577, https://doi.org/10.1016/j.jclepro.2017.03.155

\section{Copyrights}

Copyright for this article is retained by the author(s), with first publication rights granted to the journal.

This is an open-access article distributed under the terms and conditions of the Creative Commons Attribution license (http://creativecommons.org/licenses/by/4.0/). 